\title{
Learning through moderation
} Minding our language

\author{
ROSEMARY HIPKINS
}

I 'm writing this commentary just after the New Zealand Qualifications Authority (NZQA) has released the 2009 school statistics for overall achievement in the National Certificate of Educational Achievement (NCEA). This is the stuff of which league tables are constructed, but this annual event also seems to invite critical comment on other aspects of NCEA. Like league tables, these other interpretations of what the data are saying can also make headline news. This year moderation is in one reporter's sights as the "latest controversy to dog NCEA" (Sutton, 2010). Leaving aside the fact that moderation has been contentious right since the inception of NCEA-so is hardly a "latest" issue-I want to look at the impression of moderation as an activity that is cued by the language used in this and other such articles, and I suspect in many school conversations, both between teachers and with students and parents.

"Quarter of NCEA answers fail to make the grade on re-mark" proclaimed the headline. The language chosen cues assessment as consisting of question answering. It cues moderation as an act of check marking (presumably right or wrong answers to straightforward questions). In combination, these cue the familiar formal examination system which almost all newspaper readers will understand through first-hand experience. Let me contrast this very traditional interpretation of assessment and moderation with a rich professional conversation that it was my privilege to witness last year.

I attended the New Zealand Association of Teachers of English (NZATE) conference in a school break. With time up my sleeve before my own talk, I invited myself to a moderation workshop. I watched and learnt as those present debated evidence of achievement when making a convincing speech to peers. The chief moderator used video excerpts to highlight several tricky issues of teacher judgement. In one clip we observed a very confident student deliver a speech that was strong on style but very short on substance. Was this convincing? Yes, according to the teacher whose student this was. No, according to this group of experienced English teachers who felt that no speech lacking in substance could be convincing, no matter how well delivered. I hope you can see that there is no way this conversation could be construed as being about simple "marking mistakes". Rather, an informed judgement needs to be made about the appropriate weighting to be afforded to substance and to style.

Assessment tasks that entail the performance of an "authentic" task of any sort are highly unlikely to be unidimensional. Given that The New Zealand Curriculum (Ministry of Education, 2007), with new features such as the key competencies, points strongly in the direction of using knowledge, not just getting it, we can expect these sorts of on-balance judgements to become increasingly common across the full range of curriculum subjects. However, contrary to impressions created by articles such as the one cited above, making appropriate judgements is not necessarily a new challenge. Judgement calls are inevitably involved in traditional examinations as well, but they are likely to be hidden from the view of all except the markers and those who co-ordinate their work. If, like me, you were ever a member of a marking panel for the Bursary examination, you will readily recall the day-long meetings at the start of the marking, when everyone tried to thrash out a shared view of the acceptable range of answers for each question. These judgements were invisible to all but those involved, whereas NCEA moderation brings the whole act of judgement making out into the daylight. Is this a good thing, given the anxieties it seems to generate? I think it is, as I now explain.

Because moderation entails shared conversations it affords rich possibilities for teacher professional learning. Previously only markers might have gained expanded insights into the range and characteristics of expected achievement. Everyone else could only access the brief chief marker commentary-assuming they knew when and where to look for it. Returning to the speech example, I hope that the teacher concerned was able and willing to learn from the moderation feedback received. 


\section{HE WHAKAARO ANO}

At the end of the workshop I personally understood so much about the nuanced nature of evidence of achievement for this standard. I'd never before reflected in quite that way on what a complex meaning-making act a speech can be. (Standing up to deliver a keynote address right after this made me uncharacteristically nervous - all those performance experts judging me!) Had I been a teacher, I hope I would have gone back to school with a much enriched view of what I needed to explicitly teach and draw to my students' attention, which in turn would enable me to scaffold their practice of speech writing and speech making. This conversation was about so much more than following correct procedures for assessment.

In this discussion I have deliberately framed moderation as a learning activity. As I've already noted in passing, many of the learning outcomes signalled in The New Zealand Curriculum (Ministry of Education, 2007) require new types of evidence and hence new forms of assessment-teachers, not just students, have much to learn! The moderation challenge in this rapidly evolving curriculum context is that the "standard" can never reside in words on a page, no matter how carefully thought out. Rather, the standard resides in the collective constituted by: the formal standard's definition and notes; the body of tasks used to assess the standard; the range of student work generated by those tasks; and the history of judgements that builds up in relation to how and why student work meets a standard, or does not. It will be evident that most of these sources can only be generated over a period of time, and so shared professional knowledge about what constitutes the standard builds slowly but continuously as it is enacted. With this in mind, we should celebrate the learning achieved via moderation debates, not mark these out as failures of quality control (i.e., mistakes).

When NCEA was first introduced, teachers were encouraged to send in work at the boundaries between levels of achievement (not achieved, achieved, achieved with merit, achieved with excellence) so that they could check their growing understanding of the standard of work required for each level. The recent change from voluntary sampling to random sampling foregrounds an accountability framing (at the expense of learning?). The danger is that this change of practice will consolidate the view that incorrectly assigned levels of achievement are mistakes rather than matters of judgement. Consistency in judgements made using NCEA achievement standards can never be seen as a "done deal". As our curriculum understanding deepens and evolves, we can expect new standards, and revised interpretations of existing standards, to require ongoing moderation and fine-tuning. The sooner we help parents and students understand this fluid complexity, the better for our professional work.

This is not just an issue for secondary schools. With the introduction of national standards, primary schools are going to confront the same challenges very soon. We know from the NCEA experience that primary teachers face a time of intense professional learning. Teachers in every school or cluster will need to decide: which types of "evidence" (actions, work in progress, completed work) are relevant to any one standard and how different pieces of evidence collectively build to a picture of achievement consistent with the standard (so-called overall professional judgement, or OPJ). It seems fair to predict we will see repeats of the above type of media message. It's not hard to image headlines such as "Primary teachers make mistakes - too soft on students' reading". The message here has an equivalent tone to the article I've just cited. If we do not all do our bit to shift the conversation and language used to describe moderation we will find ourselves retreating to defensive positions and traditional views of learning at the very time when we need to be bold in transforming schooling to meet the conditions of the 21st century, as our national curriculum strongly signals that we should.

\section{References}

Ministry of Education. (2007). The New Zealand curriculum. Wellington: Learning Media.

Sutton, M. (2010, 11 April). Quarter of NCEA answers fail the grade on re-mark. Sunday Star Times, p. A3.

ROSEMARY HIPKINS is a chief researcher at the New Zealand Council for Educational Research.

Email: rosemary.hipkinsळnzcer.org.nz 